\title{
WATER VAPOR BARRIER PROPERTIES OF COATED AND FILLED MICROFIBRILLATED CELLULOSE COMPOSITE FILMS
}

\author{
Kelley L. Spence, ${ }^{\mathrm{a}}$ Richard A. Venditti, ${ }^{\mathrm{a}, *}$ Orlando J. Rojas, ${ }^{\mathrm{a}, \mathrm{b}}$ Joel J. Pawlak, ${ }^{\mathrm{a}}$ and \\ Martin A. Hubbe ${ }^{a}$
}

\begin{abstract}
Microfibrillated celluloses (MFCs) have mechanical properties sufficient for packaging applications but lack water vapor barrier properties in comparison to petroleum-based plastics. These properties can be modified by the use of mineral fillers, added within the film structure, or waxes, as surface coatings. In this investigation it was determined that addition of fillers resulted in films with lower densities but also lower water vapor transmission rates (WVTR). This was hypothesized to be due to decreased water vapor solubility in the films. Associated transport phenomena were analyzed by the Knudsen model for diffusion but due to the limited incorporation of chemical factors in the model and relatively large pore sizes, accurate prediction of pore diameters for filled films was not possible with this model. Modeling the filled-films with Fick's equation, however, takes into account chemical differences, as observed by the calculated tortuosity values. Interestingly, coating with beeswax, paraffin, and cooked starch resulted in MFC films with water vapor transmission rates lower than those for low density polyethylene. These coatings were modeled with a three-layer model which determined that coatings were more effective in reducing WVTR.
\end{abstract}

Keywords: Microfibrillated cellulose; MFC; Nanofibrillated cellulose; NFC; Water vapor transmission rate; Internal filler, Surface coating; Mineral fillers; Beeswax; Paraffin; Cooked starch.

Contact information: a: Department of Forest Biomaterials, North Carolina State University, Campus Box 8005, Raleigh, NC 27695 USA; b: Department of Forest Products Technology, Aalto University, P.O. Box 3320, FIN-0215, Aalto Espoo, Finland; *Corresponding author: richardv@ncsu.edu

\section{INTRODUCTION}

Cellulosic fibers have traditionally been used in packaging for a wide range of food categories such as dry, frozen, or liquid foods and beverages (Kirwan 2003; Kirwan and Strawbridge 2003). Cellophane, which is regenerated cellulose obtained from wood pulp, is also extensively used as a material for food packaging, having a water vapor permeability of $1.25 \times 10^{-9} \mathrm{~mol}^{*} \mathrm{~cm} /\left(\mathrm{cm}^{2} \mathrm{~s}^{*}\right.$ atm) (Nobile et al. 2002). A newer class of cellulosic materials, microfibrillated celluloses (MFC), developed in 1983 by Turbak et al. (1983), has emerged as a potential packaging material because of its mechanical properties. In fact, the strength of MFC-based films is a requisite that can be easily met given the fact that, at a $35 \mathrm{~g} / \mathrm{m}^{2}$ basis weight, MFC films were found to have a relatively high tensile index of $146 \mathrm{Nm} / \mathrm{g}$, elongation of 8.6\%, and an elastic modulus of $17.5 \mathrm{GPa}$ (Syverud and Stenius 2009). These MFC films have also shown low oxygen transmission rates, $17 \mathrm{~mL} / \mathrm{m}^{2}$ day, which are comparable to those of synthetic packaging based on oriented polyester ethylene vinyl alcohol. For MFC-based films, the porosity, 
which is an important criterion for packaging and barrier properties, is modifiable by drying from different solvents, which provides an advantage over melt-formed plastics. For example, the porosity for MFC-based films dried from water was as high as $28 \%$, in contrast to films dried from solvents such as methanol, ethanol, and acetone that had porosities of up to $40 \%$ (Henriksson et al. 2008). When used as a coating layer on paper, it was shown that the addition of MFC at approximately $10 \%$ of the total mass significantly reduced surface porosity and air permeability (Syverud and Stenius 2009). Although chemically modified biopolymers such as cellulose derivatives or thermoplastic starches have been widely used in packaging, renewable biopolymers are currently of central interest, as there is the potential to replace conventional petroleum-derived polymers typically used in food packaging (de Vlieger 2003).

In order to improve the performance of packaging to meet the demands of product safety, shelf-life extension, cost-efficiency, environmental burdens, and consumer convenience, innovative modified and controlled packaging materials are being developed. Currently, these materials are largely produced from fossil-derived synthetic plastics, but with increasing environmental concerns, materials derived from renewable resources are strongly being investigated as potential replacements. These materials must provide protection for products to obtain a satisfactory shelf life at the same levels as those obtained with petroleum-derived ones (Rhim 2007; Rhim and Ng 2007). Indeed, applicable materials must have adequate mechanical properties and provide a sufficient barrier to oxygen, water vapor, light, microorganisms, and contaminants in order to prevent food deterioration.

MFCs produced from TEMPO (2,2,6,6-tetramethylpiperidine)-mediated oxidation have potential uses in packaging applications and electronics. Fukuzumi et al. (2009) coated polylactic acid films with TEMPO-oxidized MFCs to improve gas barrier properties and hydrophobicity, both important properties for these applications. It is expected that the high carboxylate content after oxidation will result in the films having low resistance to water.

Previous work on water vapor transmission has shown that increasing the lignin content in MFC samples resulted in higher water vapor transmission (Spence et al. 2010): an increase of 10, 25, and 92\% when replacing bleached by unbleached fibers from hardwood, softwood with a low lignin content, and softwood with a high lignin content was noted, respectively. These results were unexpected, due to the higher initial water contact angles of the more highly lignified samples. It was hypothesized that this increase was related to a different pore structure formed between the microfibrils in the film.

Water vapor transmission rate (WVTR) can be calculated using Fick's law of diffusion if steady state diffusion and a linear concentration gradient through the material are assumed (Chinnan and Park 1995). For example, water vapor transmission through a paper sample as measured by the wet cup method is affected by the contribution of three factors (Hu et al. 2000): boundary layers of stagnant air and sample surface inside and outside the measuring cup.

For a solid polymer, WVTR is likely to occur in four main steps (Hu et al. 2000). First, water molecules adsorb onto the sample surface (e.g. inside cup surface). Water will then absorb into the sample, rapidly establishing equilibrium and further diffuse 
through the material driven by a concentration gradient. Water molecules will then exit the sample (e.g. outside cup surface) by desorbing from the surface. However, for porous materials, it is likely that molecules may pass through large, non-adsorbing pores. It is possible that films of MFC exhibit a combination of both Fickian and Knudsen diffusion mechanisms. In the case of Fickian diffusion, Fig. 1, the molecule collides with other gas molecules as it diffuses through the material. As illustrated in Fig. 1, the molecule collides mainly with pore walls; the pore diameter and roughness significantly affect the molecule trajectory. A combination of both types of diffusion results in a trajectory that involves both gas-gas and gas-wall collisions, with a frequency depending on the size and distribution of the pores.

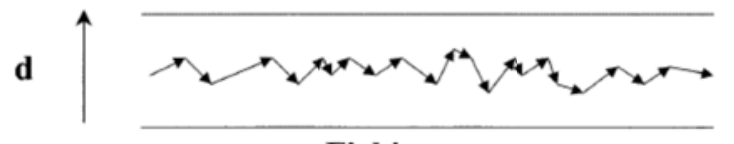

Fickian

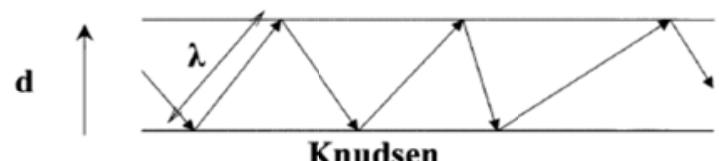

Knudsen

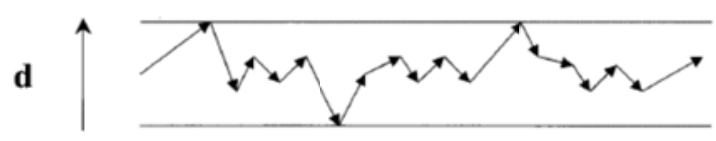

Transition Fickian/Knudsen

Fig. 1. Types of molecular diffusion (Hale et al. 2001)

It has been observed that WVTR is affected by temperature, pressure, film thickness, film density, pore structure, pore size, sample crystallinity, and hydrophilicity (Chinnan and Park 1995; Hu et al. 2000; Shogren 1997). Increasing the temperature and pressure results in higher WVTR, whereas increasing film density and film thickness results in lower WVTR. Modifying the structure of the pore network by decreasing pore size or increasing sample crystallinity should reduce the WVTR. In this work, mineral fillers were investigated in an attempt to block the pore network and decrease water vapor permeability. Starch, paraffin, and beeswax were also investigated as coatings for analysis of improved barrier properties.

\section{EXPERIMENTAL}

\section{Materials}

MFC samples were produced from bleached hardwood market pulp using a 10inch disk diameter Masuko Super Masscolloider (Masuko SangyoCo., Kawaguchi-City, Japan). Samples were processed at 3\% consistency, with no pretreatment, for 9 passes (an energy consumption of approximately 5,600 kJ/kg). The MFC diameters ranged from approximately $45 \mathrm{~nm}$ to $80 \mathrm{~nm}$. 
Kaolin clay (No. 1 filler clay, Imerys, Paris, France) with diameters of approximately $0.1-2.5 \mu \mathrm{m}$ and a density of $2.8 \mathrm{~g} / \mathrm{cm}^{3}$ and calcium carbonate (Hydrocarb 80, Omya North America, Cincinnati, Ohio) with diameters of approximately 0.5-1.0 $\mu \mathrm{m}$ and a density of $2.4 \mathrm{~g} / \mathrm{cm}^{3}$ were used as fillers (values as reported by suppliers). An ethylated starch, Ethylx (Staley Starch, Decatur, IL), was cooked at $100{ }^{\circ} \mathrm{C}$ for 25 minutes ( $0.03 \mathrm{~g}$ starch/mL water) for use as a coating and as filler. Ethylx was also used as filler, with a density of $560 \mathrm{~g} / \mathrm{cm}^{3}$, without prior cooking. Materials used for film coatings were cooked starch, beeswax, and paraffin wax. Natural beeswax (Country Lane Candle Supplies, Doylestown, PA) with a melting point of $62-64^{\circ} \mathrm{C}$ (Donhowe and Fennema 1993) and a density of $0.97 \mathrm{~g} / \mathrm{cm}^{3}$ and paraffin wax (Sigma-Aldrich, product no. 327204, St. Louis, MO) with a melting point of $53-57^{\circ} \mathrm{C}$ and a density of $0.93 \mathrm{~g} / \mathrm{cm}^{3}$ (values as reported by suppliers) were applied as solutions in heptane at a concentration of $0.03 \mathrm{~g} / \mathrm{mL}$.

\section{Methods}

MFC films were produced using a casting/evaporation technique. A portion of the MFC slurry was poured into a plastic petri dish after 10 minutes of mixing and vacuum de-aeration to produce films with a basis weight of $30 \mathrm{~g} / \mathrm{m}^{2}$ after drying. Dried films were conditioned under TAPPI standard conditions $\left(23{ }^{\circ} \mathrm{C}\right.$ and $50 \%$ relative humidity) for a minimum of $24 \mathrm{~h}$ before testing. The typical time required for drying and conditioning was 5 days.

In the case of filled samples, fillers were added to the slurry before vacuum deaeration. For coated films, films of MFC were produced using the casting/evaporation technique and allowed to dry and condition. The conditioned samples were then coated using a dipping technique. Films were submersed in glass petri dishes containing approximately $30 \mathrm{~mL}$ of solution for approximately 10 seconds, removed, and dried vertically. Films were allowed to dry between coatings. After coating, films were conditioned at $23{ }^{\circ} \mathrm{C}$ and $50 \%$ relative humidity for a minimum of 24 hours before testing.

Film thickness was determined using TAPPI Method T411 by means of a Lorentzen and Wettre Micrometer 51 instrument (L\&W, Stockholm, Sweden). The basis weight was determined using TAPPI standard T410, and the apparent film density was calculated using the measured basis weight and sample thickness. The average and standard deviation of ten measurements were reported.

Field emission scanning electron microscopy was performed with a JEOL 6400F FE-SEM (JEOL, Peabody, MA, USA) with a sputter coating of approximately $6 \mathrm{~nm}$ of $\mathrm{Au} / \mathrm{Pd}$, an accelerating voltage of $5 \mathrm{kV}$, and a working distance of $20 \mathrm{~mm}$. Fracture samples were prepared by fracturing in liquid nitrogen.

Tensile strength of the MFC films was determined using an Instron 4411 apparatus (Instron, Norwood, Massachusetts, USA) with a modified TAPPI standard testing procedure (T404, 1992). Samples were $15 \mathrm{~mm}$ wide, and the clamp span was set to $25.4 \mathrm{~mm}$. Crosshead speed was set to $4 \mathrm{~mm} / \mathrm{min}$. Tensile index, the tensile strength divided by the basis weight, was reported to account for variations in film basis weight that could skew the tensile strength results. The average and standard deviation of three measurements were reported. 
WVTR was determined using the wet cup method (Spence et al. 2010). Conditioned film samples were cut into $4 \mathrm{~cm}$ diameter circles and restrained above 50 $\mathrm{mL}$ of water in a closed container, and placed on a dynamic wetting apparatus interfaced with a computer for data acquisition. Room conditions were held constant at $23{ }^{\circ} \mathrm{C}$ and $50 \%$ relative humidity. Data were taken every 10 seconds, and the slope of the generated weight-loss curve and film thickness were used to calculate the specific WVTR in $\left(\mathrm{g} /\left(\mathrm{m}^{2} *\right.\right.$ day $\left.)\right) / \mathrm{m}$ for each sample. The average and standard deviation of three measurements were reported. The WVTR of aluminum foil was measured to be 0 $\mathrm{g} /\left(\mathrm{m}^{2 *}\right.$ day); this measurement was in agreement with literature values (Shogren 1997).

\section{RESULTS}

\section{MFC Films Containing Filler}

Adding internal mineral fillers to MFC films resulted in a decrease in density, as shown in Fig. 2. This was expected, as mineral fillers and cellulosic fibers do not bond well (Scott 1996), tending to increase the non-bonded area between the filler and the cellulose, as well as generating voids due to consolidation interference. In addition, structural differences were observed by SEM imaging (Fig. 3). The 7.5\% kaolin clay sample showed aggregates of clay; these aggregates were likely to cause a larger decrease in density by interfering further with the compaction of microfibrils, due to the presence of the larger mineral aggregates. By observing the general trends in Fig. 2 and 3, it appears that the mineral particles decreased density by interfering with microfibril consolidation, but the cooked starch did not have such an effect, because it was solubilized in the water.

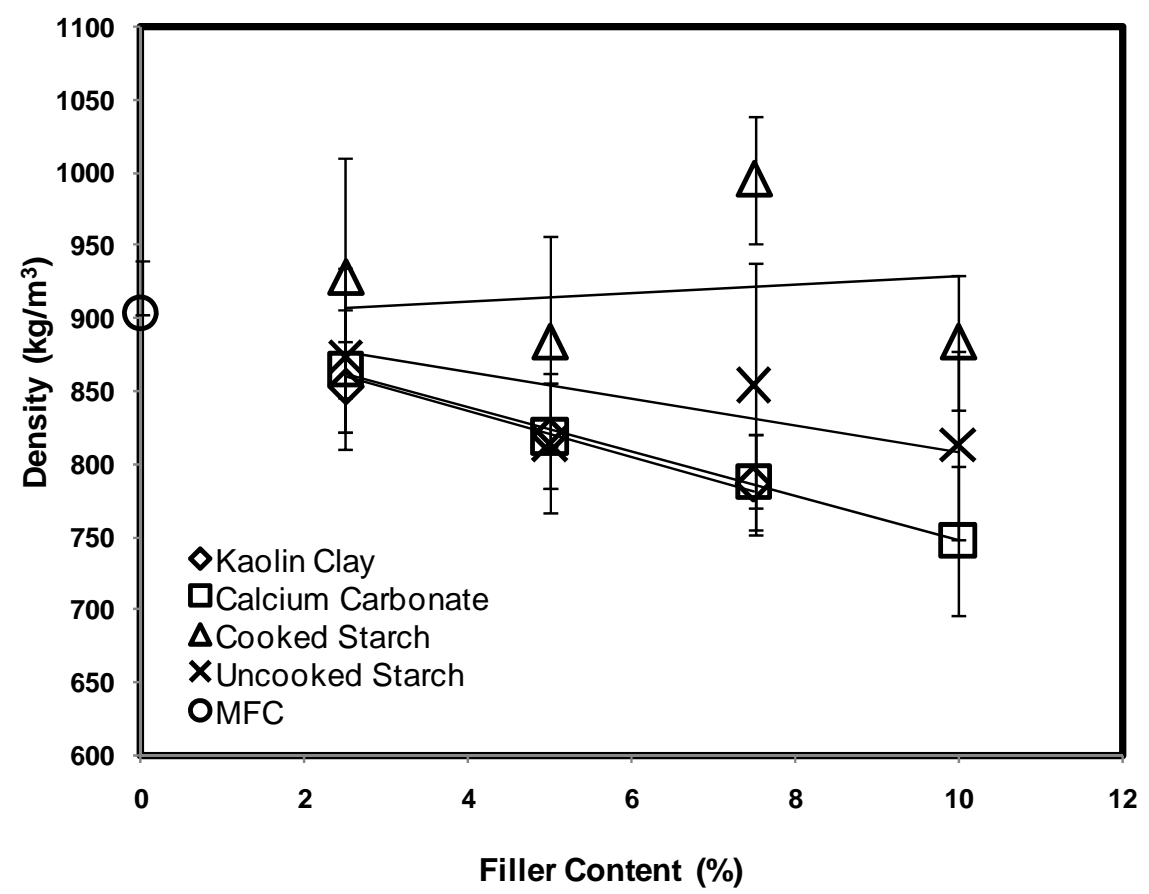

Fig. 2. Film density as related to internal filler content of MFC films 


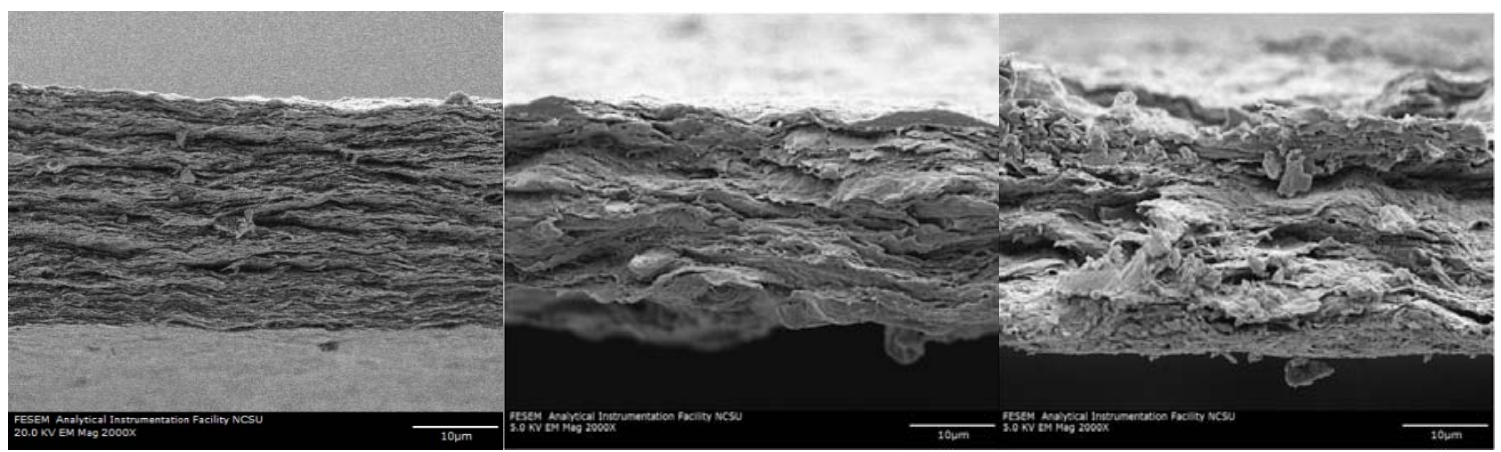

Fig. 3. Change in film compaction as observed by SEM. The figures are as follows: left - pure MFC; middle - MFC containing 2.5\% kaolin clay; right - MFC containing $7.5 \%$ kaolin clay. Scale bar provided in the black panel is equivalent to 10 microns.

The addition of 0.1-2.5 $\mu \mathrm{m}$ calcium carbonate and 0.5-10 $\mu \mathrm{m}$ kaolin clay resulted in a decrease in WVTR, as shown in Fig. 4, suggesting differences in the chemical composition of the pore network outweighing the effects of density. Kaolin clay resulted in a lower WVTR than calcium carbonate; for example, at $7.5 \%$ addition, kaolin clay reached a WVTR of $1.04\left(\mathrm{~g} / \mathrm{m}^{2} *\right.$ day $) / \mathrm{m}$ and calcium carbonate reached a WVTR of 1.69 $\left(\mathrm{g} / \mathrm{m}^{2} *\right.$ day $) / \mathrm{m}$, reductions of $51.6 \%$ and $21.4 \%$, respectively. Park et al. (2003) observed similar trends, with the addition of clay to thermoplastic starch, resulting in up to a $40 \%$ reduction in WVTR. The addition of cooked and uncooked starch resulted in an increase in WVTR, suggesting that the chemical modification of the pore network enhanced the transmission of water vapor through the film, contrary to the addition of the mineral fillers.

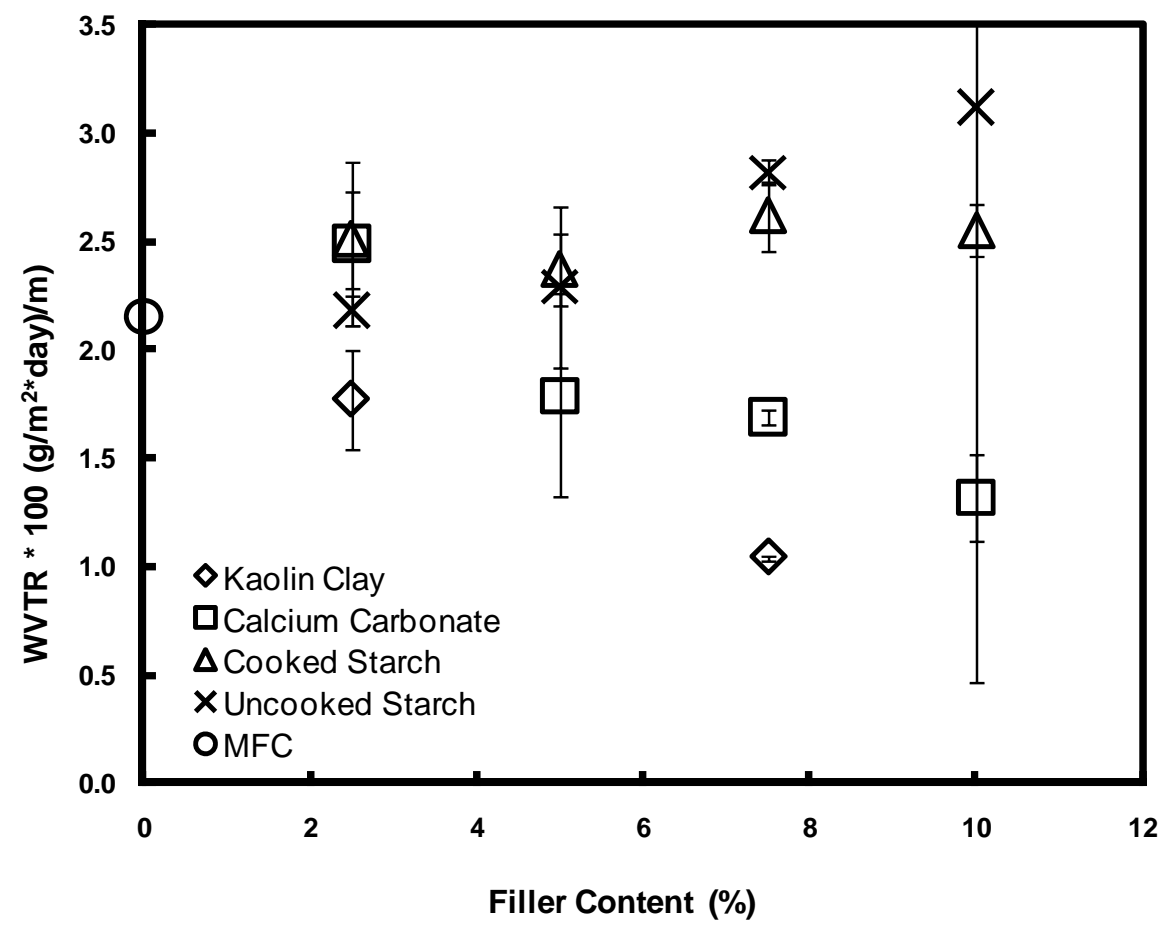

Fig. 4. Water vapor transmission rate (WVTR) as related to filler content 


\section{Surface Coatings}

An alternative method for decreasing the WVTR is to surface coat the films. As such, cooked starch was used as a coating for MFC films and resulted in a coating weight of approximately $9 \mathrm{~g} / \mathrm{m}^{2}$ on a $30 \mathrm{~g} / \mathrm{m}^{2}$ MFC film after six successive submersions of the film in the liquid. The rate of coating weight increase for paraffin wax was double that of cooked starch (coating weight of ca. $16 \mathrm{~g} / \mathrm{m}^{2}$ with six submersion and drying cycles). This reflects differences between the coatings, such as the viscosity, solvent type, wettability, and penetration. Beeswax reached a coating weight of approximately 27 $\mathrm{g} / \mathrm{m}^{2}$ with six submersions; with a pickup amount about double that of paraffin and almost four times that of cooked starch. The coating materials penetrated the MFC film pore structure to different degrees (Fig. 5). The ability of the beeswax to penetrate the MFC films more than paraffin is likely due to the chemical composition of the two waxes, differences in viscosity, and differences in surface chemistry between the materials and the microfibrillated cellulose. Beeswax consists of hydrocarbons, free fatty acids, and mostly long chain esters (Tulloch and Huffman 1972), whereas the paraffin is composed of long-chain, potentially branched, hydrocarbons. It is thought that the more linear structure of the beeswax and its lower viscosity are among the reasons for film penetration, in comparison to the paraffin. It is also possible that the beeswax is able to wet the pore structure more quickly, which promoted penetration.

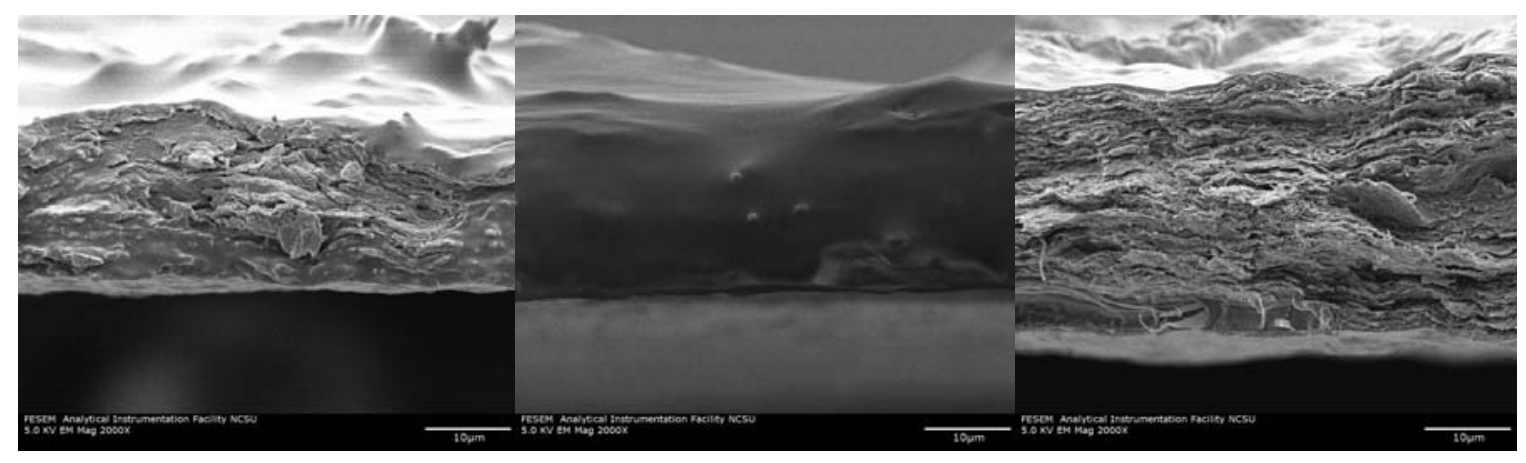

Fig. 5. Coating characteristics as observed by SEM. Figure on the left is a MFC film coated with paraffin wax $\left(2.8 \mathrm{~g} / \mathrm{m}^{2}\right)$. Figure in the center is a MFC film coated with beeswax $\left(10.2 \mathrm{~g} / \mathrm{m}^{2}\right)$. Figure on the right is a MFC film coated with cooked starch $\left(4.6 \mathrm{~g} / \mathrm{m}^{2}\right)$. All samples (film weight of $30 \mathrm{~g} / \mathrm{m}^{2}$ ) were submerged three times in the respective liquids.

Increasing the coating weight resulted in a significant decrease in WVTR, with beeswax resulting in the lowest value (Fig. 6). Low density polyethylene, LDPE, had a significantly lower WVTR compared to films from MFC; however, a coating weight of approximately $1 \mathrm{~g} / \mathrm{m}^{2}$ of beeswax, $2.5 \mathrm{~g} / \mathrm{m}^{2}$ of paraffin, and $5 \mathrm{~g} / \mathrm{m}^{2}$ of cooked starch resulted in a WVTR of approximately half that of LDPE (Fig. 6). Further increasing the coating weight of paraffin and cooked starch did not significantly decrease WVTR, suggesting that the additional coating was mainly on the surface. The ability of the beeswax to penetrate and wet the surface more easily resulted in a significantly higher coating weight and a further reduction in WVTR. This was also confirmed by SEM (Fig. 5). The differences in surface chemistry and physical structure of the waxes appear to be important for the improvement of water vapor barrier properties. 


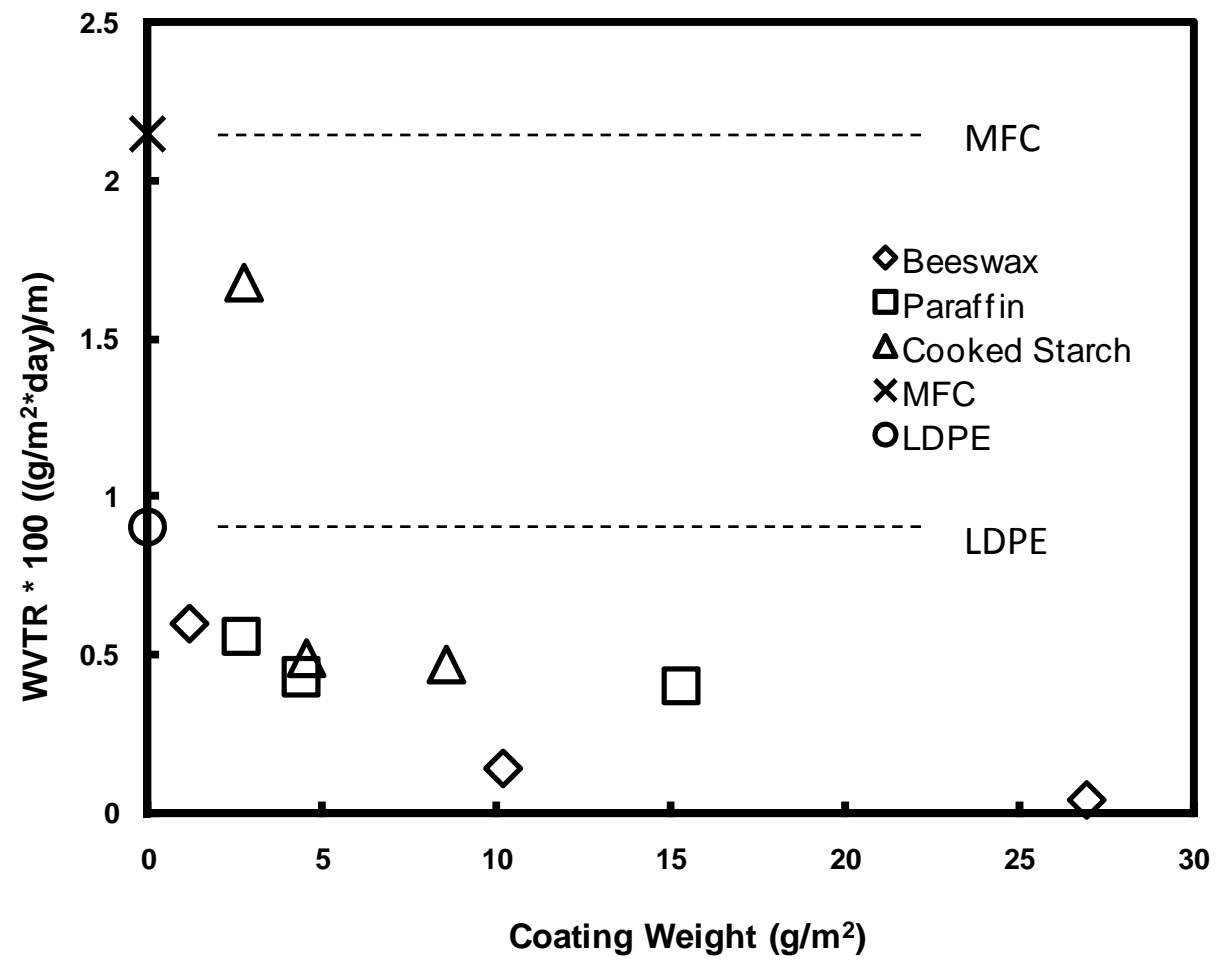

Fig. 6. Water vapor transmission rate (WVTR) of microfibrillated cellulose (MFC) films coated with beeswax, paraffin, and cooked starch at varying coating weights. Experimental variability for the WVTR measurements as reflected by $+/$ - one standard deviation would be equal to 0.0034 $\left(\mathrm{g} / \mathrm{m}^{2 \star}\right.$ day $) / \mathrm{m}$.

\section{DISCUSSION}

Previous modeling of water vapor transport through paper has shown that transport can occur by various mechanisms, such as diffusion through inter-fiber void space, Fickian diffusion, Knudsen diffusion (when the pore diameter is smaller than 10 $\mathrm{nm}$ ), surface diffusion, bulk solid diffusion within fibers, and capillary transport (Liang et al. 1990; Nilsson et al. 1993). It was theorized that the first mechanism, diffusion through inter-fiber void space, is the dominant mechanism of transport in paper, particularly in samples tested at less than 58\% relative humidity, as it occurs at the fastest rate (Nilsson et al. 1993).

It can be determined if moisture vapor transport through a MFC film can be accurately modeled using Knudsen diffusion, which can be characterized by the dimensionless Knudsen number (Geankoplis 2003):

$$
N_{K n}=\frac{\lambda}{2 \bar{r}}
$$

where $\lambda$ is the mean free path or distance a gas molecule travels before a collision with another molecule, and $r$ is the average pore radius of the material. If the value of $N_{K n}$ is 
larger than 10, the diffusion is considered to be primarily Knudsen diffusion and if it is on the order of one the molecular motion falls into the transition regime between Fickian and Knudsen diffusion (Geankoplis 2003). According to Jennings (1988), the mean free path is $66.38 \mathrm{~nm}$.

An estimated pore diameter can be calculated using previously determined MFC dimensions (Spence et al. 2010) and the assumption that MFCs have a uniform cross section that can be assumed to be equivalent to that of a circle. The pore area is calculated by assuming a square with sides equal to the diameter of the MFC is placed with corners at the center of each circle, Fig. 7. The pore area is then represented by the area of the square minus the area of the circle (four times the area of $1 / 4$ of each circle). The pore is assumed to be the shape of a square. Another geometrical model using ellipses (with a ratio of axes of 3 to 1) instead of cylinders was also used to calculate pore diameter, as MFCs are not cylindrical in shape. This model resulted in a calculated pore diameter percent difference of $73 \%$, but calculated Knudsen numbers were significantly below 10, Table 1.

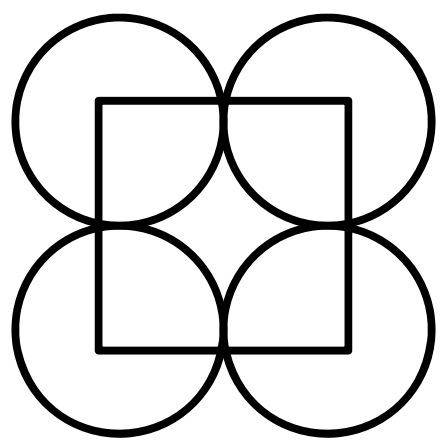

Fig. 7. Pore diameter determination assuming cylindrical MFC geometry.

Table 1. Calculated Pore Radii and Knudsen Numbers Based on Cylindrical MFC elements

\begin{tabular}{|c|c|c|c|}
\hline Sample & $\begin{array}{c}\text { Lignin } \\
\text { Content } \\
(\%)\end{array}$ & $\begin{array}{c}\text { Cylindrical } \\
\text { Approximated } \\
\text { Average Pore } \\
\text { Radius (nm) }\end{array}$ & $\begin{array}{c}\text { Knudsen } \\
\text { Number }\end{array}$ \\
\hline $\begin{array}{c}\text { Bleached } \\
\text { Hardwood }\end{array}$ & $1.3 \pm 0.1$ & $14.4 \pm 7.4$ & 2.3 \\
\hline $\begin{array}{c}\text { Unbleached } \\
\text { Hardwood }\end{array}$ & $2.4 \pm 0.4$ & $19.7 \pm 3.7$ & 1.7 \\
\hline $\begin{array}{c}\text { Bleached } \\
\text { Softwood }\end{array}$ & $0.8 \pm 0.1$ & $18.3 \pm 8.8$ & 1.8 \\
\hline $\begin{array}{c}\text { Unbleached } \\
\text { Softwood Low } \\
\text { Lignin Content }\end{array}$ & $8.8 \pm 1.8$ & $19.5 \pm 18.1$ & 1.7 \\
\hline $\begin{array}{c}\text { Unbleached } \\
\text { Softwood High } \\
\text { Lignin Content }\end{array}$ & $13.8 \pm 0.7$ & $61.4 \pm 69.0$ & 0.5 \\
\hline
\end{tabular}


The effect of pore diameter on film density can be elucidated using a similar model, Fig. 8. In this model, a cylinder with diameter $r$ and length $a$ is placed in the middle of a cube with sides of length $a$. The cube represents cellulose, with a density of $1.6 \mathrm{~g} / \mathrm{cm}^{3}$, and the cylinder represents a pore. Assuming $a$ to be $50 \mathrm{~nm}$, a reasonable estimate for the width of two microfibrils with diameter $25 \mathrm{~nm}$ placed next to each other, the radius of the pore, $r$, can be varied to determine the effect of radius on material density, Fig. 8. As expected, increasing the pore radius resulted in decreased material density, especially above $15 \%$.

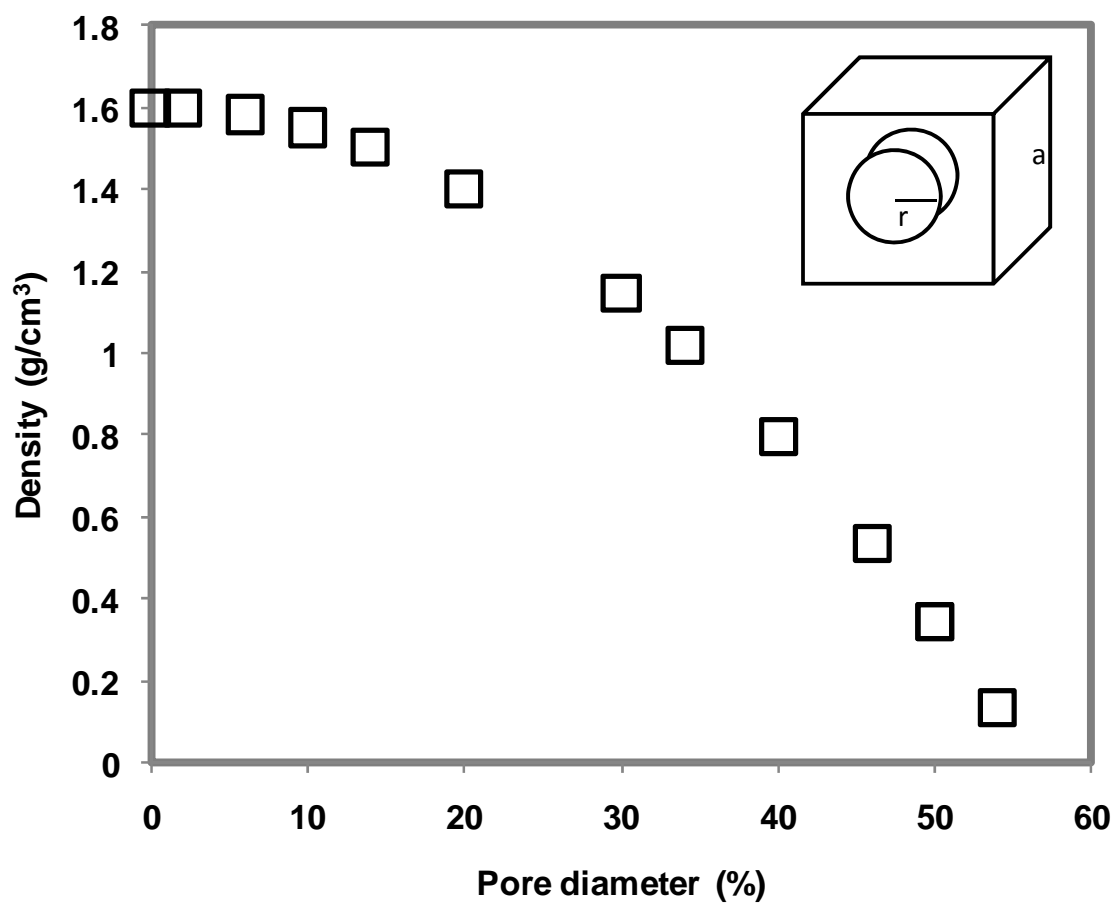

Fig. 8. Effect of pore diameter (as calculated as a percent of a side of a cube with length, a) on density and a geometrical model for determining the effect of pore size on density

The Knudsen numbers calculated using Equation (1) were less than 10; therefore it is not expected that Knudsen diffusion is the dominant type of diffusion. Because of the expected wide range of pore diameters in the MFC films, and the pore size comparable to the mean free path, with Knudsen numbers being in the order of 1 indicating transition behavior, it is still beneficial to obtain information from modeling these materials using Knudsen diffusion. The equation for molar flux for Knudsen diffusion $\left(\mathrm{N}_{\mathrm{A}}\right)$ in the $\mathrm{z}$-direction is defined as (Geankoplis 2003):

$$
N_{A}=-D_{K A} \frac{d c_{A}}{d z}
$$

where $D_{K A}$ is the Knudsen diffusivity $\left(\mathrm{m}^{2} / \mathrm{s}\right)$, and $d c_{a} / d z$ is the $z$ component of the gradient of concentration. The concentrations, $c_{i}$ and $c_{e}\left(\mathrm{~mol} / \mathrm{m}^{3}\right)$, can be calculated using the following equation, with $\mathrm{RH}_{\text {local }}$ equal to $93 \%$ and $53 \%$ for the interior and exterior 
surface in mol/L, respectively, due to the movement of water vapor through stagnant air near the film surfaces (Radhakrishnan et al. 1998),

$$
c=\frac{R H_{\text {local }} \times P_{\text {sat }}}{100 R T}
$$

where $R H_{\text {local }}$ is the local relative humidity, $P_{\text {sat }}$ is the vapor pressure $(\mathrm{Pa})$ at temperature $T(\mathrm{~K})$, and $R$ is the universal gas constant $\left(8.314 \mathrm{~m}^{3} * \mathrm{~Pa} / \mathrm{mol} * \mathrm{~K}\right)$. The variable $D_{K A}$ is defined as,

$$
D_{K A}=97.0 \bar{r}\left(\frac{T}{M_{A}}\right)^{1 / 2}
$$

where $T$ is temperature $(\mathrm{K}), M_{A}$ is the molar mass $(\mathrm{g} / \mathrm{mol})$, and $r$ is the average pore diameter (m). Equations (2) and (4) can be solved using WVTR data to estimate the average pore radius in the material and the Knudsen number (Table 2). The average SEM pore radius was significantly larger than that from the diffusion-calculated pore radius, likely due to the large distribution of MFC diameters. The diffusion estimated pore radii were in the range of the SEM calculated pore radii when considering the standard deviation in the SEM measurements, verifying the model for the case of the unfilled MFC films.

Films previously produced from MFCs of different chemical compositions and different processing methods, were determined to have higher tensile strength and lower moisture vapor transmission rates at higher densities, likely the result of a higher density of bonding and a more collapsed pore network, respectively. As observed using the cylinder and cube model, increasing the pore diameter resulted in a lower density and, in return, should result in an increase in WVTR. This was observed in the case of the addition of uncooked starch, the addition of which resulted in a decreased density, calculated average pore radius, and increased WVTR. This trend was not observed, however, in the case of the mineral fillers, in which density was shown to decrease, but WVTR and calculated average pore radius decreased. This may be explained in the context of permeability (P):

$$
P=D * S
$$

In this expression $D$ is the diffusion coefficient, and $S$ is the solubility of the vapor in the material. The fillers added to the system decreased the water vapor transmission rate (or $P$ ) perhaps due to the lower solubility of the water vapor in the filler materials.

The small Knudsen numbers below 10 in Table 2 indicate that the transport is not dominated by Knudsen diffusion. The observations for the samples containing mineral fillers based on pore diameter and density results and the Knudsen diffusion derivation should be considered with caution since the $N_{K n}$ is in the order of unity. The density and pore diameter observations with the addition of uncooked starch were as expected. These two results indicate the importance of chemistry on water vapor transport, as well as the limits of the utilization of the Knudsen diffusion model. 
Table 2. Knudsen Number and Calculated Pore Radius of MFC Films Containing Fillers and Coated MFC Films

\begin{tabular}{|c|c|c|c|}
\hline Sample & $\begin{array}{c}\text { WVTR } \times 100 \\
\left(\left(\mathrm{~g} / \mathrm{m}^{2 *} \text { day }\right) / \mathrm{m}\right)\end{array}$ & $\begin{array}{c}\text { Calculated } \\
\text { Average Pore } \\
\text { Radius }(\mathrm{nm})\end{array}$ & $\begin{array}{c}\text { Calculated } \\
\text { Knudsen Number }\end{array}$ \\
\hline MFC & 2.15 & 7.70 & 4.3 \\
\hline Kaolin Clay 2.5\% & 1.77 & 6.32 & 5.2 \\
\hline Kaolin Clay 7.5\% & 1.04 & 3.72 & 8.9 \\
\hline Calcium Carbonate 2.5\% & 2.49 & 8.90 & 3.7 \\
\hline Calcium Carbonate 5\% & 1.79 & 6.40 & 5.2 \\
\hline Calcium Carbonate 7.5\% & 1.69 & 6.04 & 5.5 \\
\hline Calcium Carbonate 10\% & 1.32 & 4.72 & 7.0 \\
\hline Uncooked Starch 2.5\% & 2.18 & 7.79 & 4.3 \\
\hline Uncooked Starch 5\% & 2.29 & 8.18 & 4.1 \\
\hline Uncooked Starch 7.5\% & 2.82 & 10.07 & 3.3 \\
\hline Uncooked Starch 10\% & 3.12 & 11.15 & 3.0 \\
\hline Cooked Starch 2.5\% & 2.51 & 8.97 & 3.7 \\
\hline Cooked Starch 5\% & 2.37 & 8.47 & 3.9 \\
\hline Cooked Starch 7.5\% & 2.62 & 9.36 & 3.5 \\
\hline Cooked Starch 10\% & 2.55 & 9.11 & 3.6 \\
\hline
\end{tabular}

In the case of starch, the added material has a similar chemical composition to the cellulose and the diameter appears to be effectively modeled by Knudsen diffusion. The addition of mineral fillers however, introduced different chemistries and was not successfully modeled by Knudsen diffusion, indicating the need for examining another diffusion model.

Previous work by Hale et al. (2001) utilizing a microporous polyethylene/calcium carbonate film, showed that the moisture vapor transport could be modeled using Fick's law of diffusion and that Knudsen diffusion calculations did not accurately describe the process of molecular diffusion. Others have modeled paper using Fick's diffusion (Radhakrishnan et al. 1998). The utilization of the Knudsen diffusion coefficient accounts only for the motion of the individual molecules based on pore size, whereas Fick's model accounts for the motion of all the molecules under the influence of a concentration gradient (Malek and Coppens 2003). The diffusion is also affected by material chemistry. As the microfibrillated cellulose film is a complex structure, it is important to consider the concentration gradient using Fick's law. Results from the MFC films containing filler were evaluated by using Fick's law due to the chemical limitations of the Knudsen model. It was assumed that vapor transmission in MFC followed Fick's law, so that the flux, as measured by WVTR, can be written as follows (Radhakrishnan et al. 1998),

$$
J=\frac{W}{A}=\frac{D_{e f f}}{H}\left(c_{i}-c_{e}\right)
$$

where $J$ is the flux of water vapor $\left(\mathrm{mol} / \mathrm{cm}^{2} * \mathrm{~s}\right), W$ is the slope of the weight-loss curve (mol/s), $A$ is the area of the sample through which the water diffuses, $D_{\text {eff }}$ is the effective diffusion coefficient $\left(\mathrm{cm}^{2} / \mathrm{s}\right), H$ is the film thickness $(\mathrm{cm})$, and $c_{i}$ and $c_{e}$ are the water 
vapor concentrations $\left(\mathrm{mol} / \mathrm{cm}^{3}\right)$ on the interior and exterior film surface, respectively, as calculated by Equation 3 .

These two equations can be solved for $D_{\text {eff }}$ after determining the other experimental variables. It is hypothesized that $D_{\text {eff }}$ is composed of two parts, the diffusivity related to the transport in the material pores, and the diffusivity related to the transport into the surface of the material (Defrenne et al. 2009). This can be represented as follows,

$$
D_{e f f}=D_{a} \frac{\varepsilon}{\tau_{p}}+D_{f} \frac{(1-\varepsilon)}{\tau_{f}}
$$

where $D_{a}$ is the open space diffusivity (pore space), $D_{f}$ is the intrinsic diffusivity of moisture into the fibers, $\varepsilon$ is the void fraction of the structure, and $\tau$ is tortuosity, the net increase of the length of the diffusion path. It is theorized that the diffusion of water vapor through a porous material is governed by void fraction and tortuosity (Defrenne et al. 2009). Void fraction was calculated using a linear mixing rule and densities of 1.6 $\mathrm{g} / \mathrm{cm}^{3}$ for cellulose and filler densities as stated in the materials section. It is noted that conventional paper testing methods used here to determine the thickness of the films are likely to overestimate the thickness, and, therefore, underestimate the film density (Chinga-Carrasco and Syverud 2010), resulting in over-estimated void fractions.

Defrenne et al. calculated an intrinsic wood fiber diffusivity ratio to relate $D_{f}$ to $D_{a}$. The value of this ratio is 0.02 for highly refined fibers (Defrenne et al. 2009). Assuming microfibrils are similar to highly refined fibers, then the diffusivity term related to the pore network is much larger than the diffusivity term related to the fibers and Eqn. (7) simplifies to:

$$
D_{e f f}=D_{a} \frac{\varepsilon}{\tau_{p}}
$$

Equations 6 and 8 and the estimated void volume values can be used to calculate tortuosity, Table 3. The path length is determined by multiplying the tortuosity by the film thickness; this length is the estimated distance a molecule of water vapor would travel to exit the film, Fig. 9. For reference, a softwood hand-sheet is expected to have a tortuosity of approximately 0.7 and a hardwood hand-sheet (with finer fiber elements) is expected to have a tortuosity of approximately 1.3 .

The addition of the mineral fillers has been shown to modify the pore network by the introduction of different material chemistries, and reduce the WVTR. This was observed in the case of the smaller, water-insoluble fillers, the calcium carbonate and the kaolin clay; however, when void volume was calculated using material densities, the addition of these fillers increased the void volume of the films. Only the addition of cooked starch internally resulted in a lower void volume than the original MFC film. The estimated void volumes and tortuosity values (Table 3) show that even though the carbonate and kaolin fillers increased void volume, an increase in tortuosity was observed. 
Table 3. Tortuosity and Void Volume of MFC Films Containing Fillers

\begin{tabular}{|c|c|c|c|c|}
\hline Sample & $\begin{array}{c}\text { WVTR } \times 100 \\
\left(\left(\mathrm{~g} / \mathrm{m}^{2 \star} \text { day }\right) / \mathrm{m}\right.\end{array}$ & $\begin{array}{c}\text { Estimated } \\
\text { Void Fraction }\end{array}$ & Tortuosity & $\begin{array}{c}\text { Path length } \\
(\mu \mathrm{m})\end{array}$ \\
\hline MFC & $2.15 \pm 0.17$ & 0.44 & 3.57 & 129 \\
\hline Kaolin Clay 2.5\% & $1.77 \pm 0.23$ & 0.48 & 4.76 & 178 \\
\hline Kaolin Clay 7.5\% & $1.04 \pm 0.01$ & 0.54 & 9.09 & 380 \\
\hline Calcium Carbonate 2.5\% & $2.49 \pm 0.38$ & 0.47 & 3.30 & 123 \\
\hline Calcium Carbonate 5\% & $1.79 \pm 0.47$ & 0.50 & 4.94 & 192 \\
\hline Calcium Carbonate 7.5\% & $1.69 \pm 0.04$ & 0.53 & 5.49 & 229 \\
\hline Calcium Carbonate 10\% & $1.32 \pm 0.20$ & 0.55 & 7.42 & 325 \\
\hline Uncooked Starch 2.5\% & $2.18 \pm 0.07$ & 0.45 & 3.61 & 130 \\
\hline Uncooked Starch 5\% & $2.29 \pm 0.37$ & 0.47 & 3.66 & 132 \\
\hline Uncooked Starch 7.5\% & $2.82 \pm 0.06$ & 0.44 & 2.75 & 109 \\
\hline Uncooked Starch 10\% & $3.12 \pm 2.65$ & 0.46 & 2.57 & 104 \\
\hline Cooked Starch 2.5\% & $2.51 \pm 0.22$ & 0.41 & 2.92 & 102 \\
\hline Cooked Starch 5\% & $2.37 \pm 0.17$ & 0.44 & 3.25 & 127 \\
\hline Cooked Starch 7.5\% & $2.62 \pm 0.16$ & 0.36 & 2.42 & 95 \\
\hline Cooked Starch 10\% & $2.55 \pm 0.12$ & 0.43 & 2.95 & 118 \\
\hline
\end{tabular}
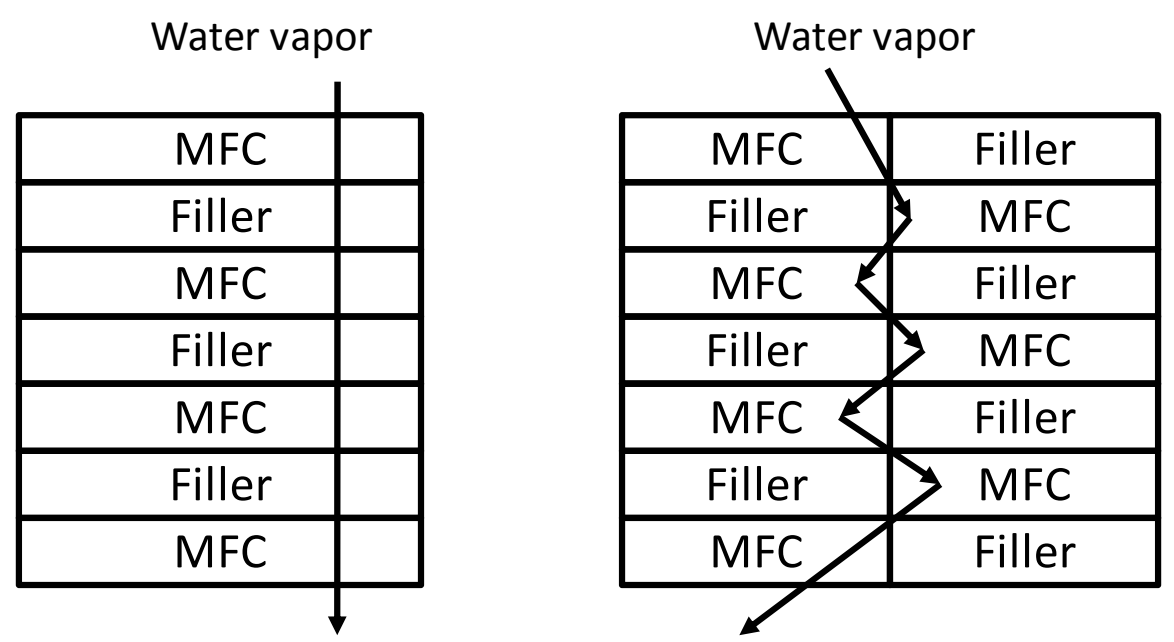

Fig. 9. Potential paths of water vapor transport, depending on filler chemistry

The fillers added to the system decreased the water vapor transmission rate likely due to a lower solubility of the water vapor through these materials. This is indicated in Table 3 by the increased tortuosity and path length, as the water vapor molecule must travel around the mineral fillers, Fig. 9. No significant change in WVTR for the cooked starch was observed, likely due to the similar densities and solubility of water vapor molecules in the cooked starch-filled and unfilled films.

In the case of beeswax, the addition of material did not decrease the film density, as shown in Fig. 10. This suggests that the coating penetrated the film and closed the pore network, in agreement with Fig. 5. The cooked starch and the paraffin coating resulted in a decrease in film density, as expected when a coating is placed on the surface, 
Fig. 10, suggesting a multiple layer structure. In the case of paraffin, the initial addition of mass did not result in a decrease in density, likely due to the filling of surface pores. Additional paraffin resulted in a decrease in density, suggesting surface coating. The results were similar in the case of cooked starch.

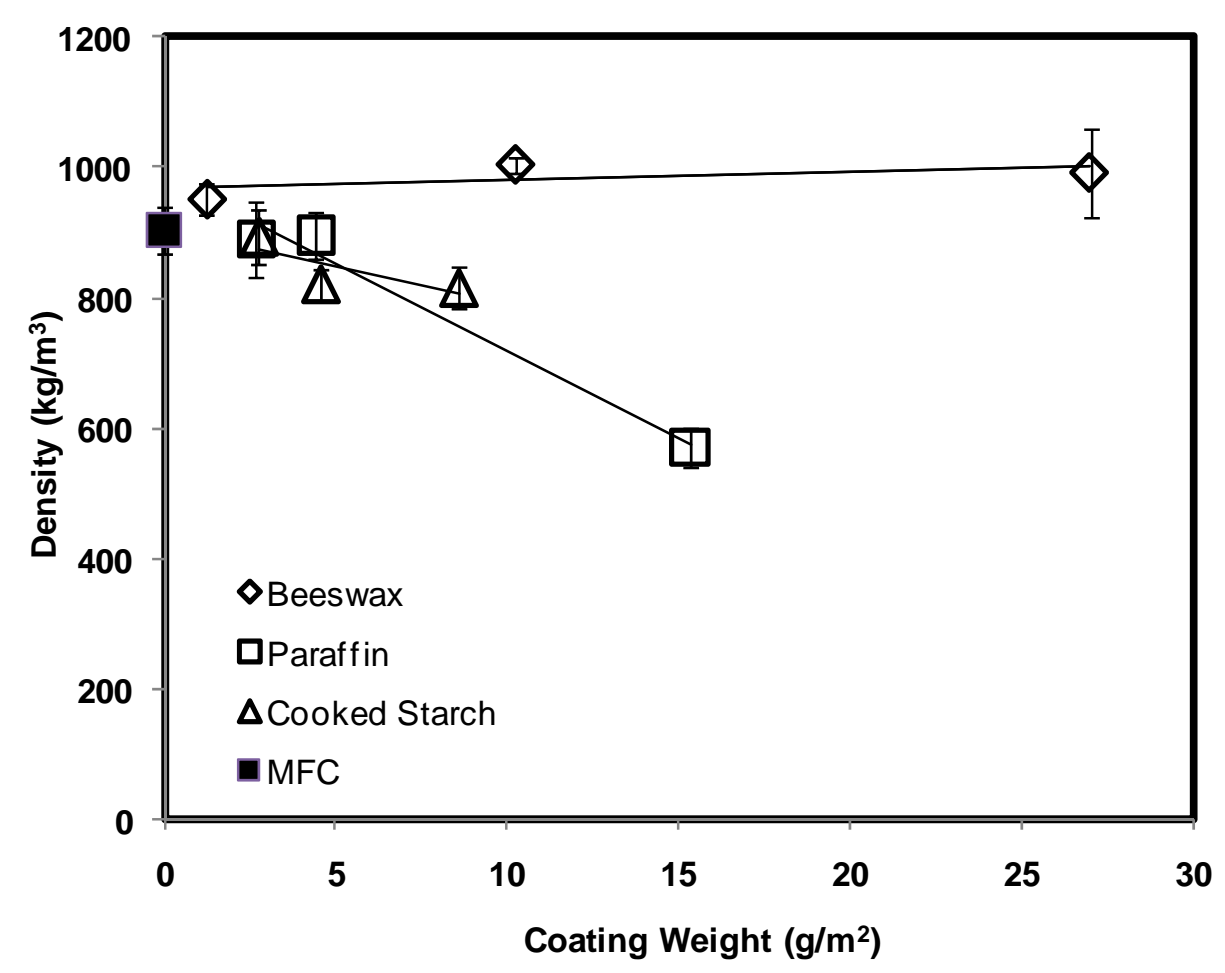

Fig. 10. Density versus coating weight for MFC film samples

The theoretical WVTR of the coated films can be calculated using a multiple layer model, Fig. 11, based on a double-sided coating. A comparison between the theoretical WVTR and the actual WVTR may indicate if film pore penetration occurred.

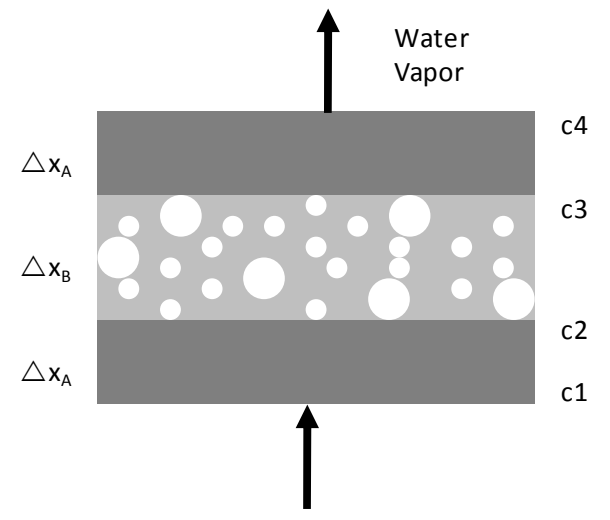

Fig. 11. Model for water vapor transmission rate through multiple layers in a series. Dark gray areas represent coatings, white areas represent pores, and light gray areas represent MFC film. 
To calculate the theoretical WVTR using the model, it was assumed that there was no pore penetration by the coating material and there was no accumulation of water vapor in the film. The WVTR was then calculated by the following equation,

$$
W V T R\left(\frac{m o l}{m^{2} * s}\right)=\frac{\Delta C}{\sum R}
$$

where $\triangle C$ is the change in concentration (as calculated by Eqn. 3) and $R$ is the sum of the resistance to water vapor transport, as defined as,

$$
R=\frac{x}{k A}
$$

where $R$ is the resistance in units of $\mathrm{s} / \mathrm{m}, x$ is film thickness in meters, $k$ is a transfer coefficient in $\mathrm{s}^{-1}$, and $A$ is the film area in $\mathrm{m}^{2}$. An $R$ value is calculated for each layer in the model, Fig. 11. The transfer coefficient for MFC films was calculated to be $2.4 \times 10^{-5}$ $\mathrm{s}^{-1}$ using the WVTR of the pure MFC film. WVTR values of $1.82 \times 10^{-6}$ and $2.78 \times 10^{-6}$ $\mathrm{mol} /\left(\mathrm{m}^{2 *} \mathrm{~s}\right)$ were obtained from literature for beeswax (Donhowe and Fennema 1993) and paraffin (Martin-Polo et al. 1992). The conditions for these values from the literature were used to determine transfer coefficients of $3.58 \times 10^{-6}$ and $5.1 \times 10^{-8} \mathrm{~s}^{-1}$ for paraffin and beeswax, respectively. The estimated and measured WVTRs are shown in Table 4.

Table 4. Estimated and Measured WVTR for Coated MFC Films

\begin{tabular}{|c|c|c|c|c|}
\hline Sample & $\begin{array}{c}\text { Estimated } \\
\text { WVTR } \\
\left(\mathrm{mol} /\left(\mathrm{m}^{2 *} \mathrm{~s}\right)\right)\end{array}$ & $\begin{array}{c}\text { Measured } \\
\text { WVTR } \\
\left(\mathrm{mol} /\left(\mathrm{m}^{2} \mathrm{~s}\right)\right)\end{array}$ & $\begin{array}{c}\text { Percent } \\
\text { Difference }(\%)\end{array}$ & $\begin{array}{c}\text { Estimated } \\
\text { WVTR Based } \\
\text { on Coating } \\
\left(\mathrm{mol}^{2}\left(\mathrm{~m}^{2} \mathrm{~s}\right)\right)\end{array}$ \\
\hline MFC & --- & $3.81 \times 10^{-4}$ & --- & --- \\
\hline $\begin{array}{c}\text { Beeswax Coated } \\
\text { MFC }\end{array}$ & $1.70 \times 10^{-6}$ & $6.82 \times 10^{-6}$ & 75.1 & $1.71 \times 10^{-6}$ \\
\hline $\begin{array}{c}\text { Paraffin Coated } \\
\text { MFC }\end{array}$ & $1.24 \times 10^{-6}$ & $6.75 \times 10^{-5}$ & 98.2 & $1.24 \times 10^{-6}$ \\
\hline
\end{tabular}

The model-estimated WVTR for the paraffin was lower than for the beeswax. This was expected, as Donhowe and Fennema (1993) found that films of pure beeswax had lower water vapor transmission rates when compared to other waxes such as candelilla, carnauba, and microcrystalline, paraffin, and high density polyethylene. Interestingly, estimating the WVTR based on just the coating resulted in WVTRs approximately equal to the calculated value of the composite. This implies that the surface coating is the limiting factor for moisture vapor transport. The percent difference for beeswax and paraffin were $75 \%$ and $98 \%$, respectively. This could be due to differences in the WVTR values found in the literature as compared to the actual materials used in this study and the fact that both coatings penetrated the surface.

The estimated water vapor transmission rate can be significantly affected by the mass transfer coefficient, $k$. In the case of the model, the mass transfer coefficients were determined by using WVTR values and sample characterization in the literature. When 
calculating the mass transfer coefficient using the WVTR of the measured samples, the values were significantly higher than those found in the literature, particularly in the case of the paraffin. The larger difference in the case of the paraffin was possibly due to defects in the film, i.e., the paraffin could have cracks in the coating, as it is likely less pliable than the beeswax, and these cracks would more easily allow the transport of water vapor. This was also supported by the fact that the estimated WVTR for the paraffin is on the same order of magnitude of the beeswax, but the measured value was an order of magnitude larger for the paraffin.

\section{CONCLUSIONS}

1. Coating microfibrillated cellulose (MFC) films with cooked starch, beeswax, or paraffin resulted in WVTRs lower than that of low density polyethylene, likely due to surface pore closure and filling of the pore network.

2. Moisture vapor transport through MFC films could successfully be modeled by Fickian diffusion. Knudsen diffusion predicted pore diameter trends for unfilled samples and samples with similar chemistries, but predictions of samples with different chemistries were unreliable.

3. A multilayer structure was used to model the studied structures to explain differences between the beeswax and paraffin coated MFC films. This analysis demonstrated that the coating was the most important resistance to water vapor transport of the composite.

\section{ACKNOWLEDGMENTS}

This project was supported by the USDA/CSREES Higher Education Food and Agricultural Sciences National Needs Graduate and Post-Graduate Fellowship Grants program, grant number 2007-38420-17772. We would also like to thank Kimberly Barnes, a member of the NC SEED program for assistance in film production and testing and Sa Yong Lee for previous work with the internal addition of starch to MFC films.

\section{REFERENCES CITED}

Chinga-Carrasco, G., and Syverud, K. (2010). "Computer-assisted quantification of the multi-scale structure of films made from nanofibrillated cellulose,” Journal of Nanoparticle Research 12, 841-851.

Chinnan, M., and Park, H. (1995). "Effect of plasticizer level and temperature on water vapor transmission of cellulose-based edible films," Journal of Food Process Engineering 18, 417-429.

de Vlieger, J. J. (2003). "Green plastics for food packaging," Novel Food Packaging Techniques, R. Ahvenainen (ed.), CRC Press LLC, New York. 
Defrenne, Y., Zhdankin, V., Takagaki, S., Ramaswamy, S., Lavrykov, S., and Ramarao, B. (2009). "Multi-scale moisture transport in paper: Impact of pore and fiber tortuosity \& anisotropy," Proc., Advances in Pulp and Paper Research 455-473.

Donhowe, G., and Fennema, O. (1993). "Water vapor and oxygen permeability of wax films," Journal of the American Oil Chemists' Society 70(9), 867-873.

Fukuzumi, H., Saito, T., Iwata, T., Kumamoto, Y., and Isogai, A. (2009). "Transparent and high gas barrier films of cellulose nanofibers prepared by TEMPO-mediated oxidation," Biomacromolecules 10(1), 162-165.

Geankoplis, C. J. (2003). Transport Processes and Separation Process Principles, Prentice Hall, Upper Saddle River, New Jersey.

Hale, W., Dohrer, K., Tant, M., and Sand, I. (2001). "A diffusion model for water vapor transmission through microporous polyethylene $/ \mathrm{CaCO}_{3}$ films," Colloids and Surfaces A: Physicochem. Eng. Aspects 187-188, 483-491.

Henriksson, M., Berglund, L., Isaksson, P., Lindstrom, T., and Nishino, N. (2008). "Cellulose nanopaper structures of high toughness," Biomacromolecules 9(6), 15791585.

Hu, Y., Topolkaraev, V., Hiltner, A., and Baer, E. (2000). "Measurement of water vapor transmission rate in highly permeable films," Journal of Applied Polymer Science 81, 1624-1633.

Jennings, S.G. (1988). “The mean free path in air,” Journal of Aerosol Science 19, 159166.

Kirwan, M. J. (2003). "Paper and paperboard packaging," Food Packaging Technology, R. Coles, D. McDowell, and M. J. Kirwan (eds.), CRC Press LLC, Boca Raton, 241281.

Kirwan, M. J., and Strawbridge, J. W. (2003). "Plastics in food packaging," Food Packaging Technology, R. Coles, D. McDowell, and M. J. Kirwan (eds.), CRC Press LLC, Boca Raton, 174-240.

Liang, B., Fields, R. J., and King, J. C. (1990). "The mechanisms of transport of water and n-propanol through pulp and paper," Drying Technology 8(4), 641-665.

Lovegren, N., and Feuge, R. (1954). "Pemeability of acetostearin products to water vapor,” Agricultural and Food Chemistry 2(11), 558-563.

Nilsson, L., Wilelmsson, B., and Stenstrom, S. (1993). "The diffusion of water vapor through pulp and paper," Drying Technology 11(6), 1205-1225.

Nobile, M. A., Fava, P., and Piergiovanni, L. (2002). "Water transport properties of cellophane flexible films intended for food packaging applications," Journal of Food Engineering 53, 295-300.

Martin-Polo, M., Mauguin, C., and Voilley, A. (1992). "Hydrophobic films and their efficiency against moisture transfer. 1. Influence of the film preparation technique,” Jounral of Agricultural Food Chemistry 40, 407-412.

Park, H., Lee, W., Park, C., Cho, W., and Ha, C. (2003). "Environmentally friendly polymer hybrids, Part 1. Mechanical, thermal, and barrier properties of thermoplastic starch/clay nanocomposites," Journal of Materials Science 38, 909-915.

Radhakrishnan, H., Chatterjee, S., and Ramarao, B. (1998). "Moisture transport through a bleached kraft paperboard stack in a diffusion cup apparatus," ESPRI, Syracuse, NY, 62-76. 
Rhim, J. (2007). "Potential use of biopolymer-based nanocomposite films in food packaging applications," Food Science and Biotechnology 16(5), 691-709.

Rhim, J., and Ng, P. (2007). "Natural biopolymer-based nanocomposite films for packaging applications," Critical Reviews in Food Science and Nutrition 47(4), 411433.

Scott, W. (1996). Principles of Wet End Chemistry. TAPPI Press, Atlanta, GA. 69-76.

Shogren, R. (1997). "Water vapor permeability of biodegradable polymers," Journal of Environmental Polymer Degradation 5(2), 91-95.

Spence, K., Venditti, R., Rojas, O., Habibi, Y., and Pawlak, J. (2010). "The effect of chemical composition on microfibrillar cellulose films from wood pulps: Water interactions and physical properties for packaging applications," Cellulose 117, 835848.

Syverud, K., and Stenius, P. (2009). "Strength and barrier properties of MFC films," Cellulose 16, 75-85.

Terashima, N., Kitano, K., Kojima, M., Yoshida, M., Yamamoto, H., and Westermark, U. (2009). "Nanostructural assembly of cellulose, hemicellulose, and lignin in the middle layer of secondary wall of ginkgo tracheid," Journal of Wood Science 55(6), 409-416.

Turbak, A., Snyder, F., and Sandberg, K. (1983). "Microfibrillated cellulose: A new cellulose product: Properties, uses, and commercial potential," Journal of Applied Polymer Science: Applied Polymer Symposium 37, 815-827.

Article submitted: April 27, 2011; Peer review completed: June 7, 2011; Revised version accepted: Sept. 7, 2011; Published: Sept. 14, 2011. 